\title{
ZS Research Suare \\ FAK displacement shows promise in combating cancer progression
}

loanna Antoniades

Maria Kyriakou

Anna Charalambous

Katerina Kalalidou

Andri Christodoulou

Maria Christoforou

Paris A. Skourides

\section{Video Byte}

Keywords: RS_FAK_Displacement

Posted Date: February 25th, 2021

DOI: https://doi.org/10.21203/rs.3.rs-275950/v1

License: (c) (i) This work is licensed under a Creative Commons Attribution 4.0 International License.

Read Full License 


\section{Abstract}

Focal adhesion kinase, or FAK, is a tyrosine kinase overexpressed in several types of cancers that plays a critical role in tumor progression. Numerous inhibitors targeting FAK and its functions have been developed, with varying degrees of success. A recent study reports a new approach that targets focal adhesions, the primary sites on cells where FAK exerts its activity. The approach centers on the use of polypeptides composed of LD motif dimers. Experiments showed that use of such polypeptides prevents FAK localization at focal adhesions in a controlled and dose dependent manner. The polypeptide does so without affecting the localization of other major focal adhesion proteins such as paxillin, a protein that helps adhere cells to the extracellular matrix. Researchers found that the polypeptide inhibited FAKdependent downstream integrin signaling. And unlike current inhibitors, the polypeptide also blocked FAK's scaffolding functions. Further experiments demonstrated that the polypeptide expression could inhibit the invasion of breast cancer cells. This study targets a key mechanism and sets the stage for the generation of synthetic compounds that could potentially be used as anti-metastatic drugs. 